\title{
A new Heat Pipe Cooling Device
}

\author{
Comanescu, D.; Comanescu, A.; \\ FilipoiU, I. D. \& Alionte, C.G.
}

Abstract: The paper presents a specific application of fractals, which are used for a heat pipe cooling device design. A heat pipe is a simple device that can quickly transfer heat from one point to another. This new device was developed for some years in Politehnica University of Bucharest by a group of multi-disciplinary group researchers lead by this paper authors. To investigate the cooling characteristics it has been used three Peano fractals structures: Hilbert, Hutchinson and Koch curve. The design was validated through basic experimental tests.

Key words: heat-pipe, fractals, Peano, curve, cooling
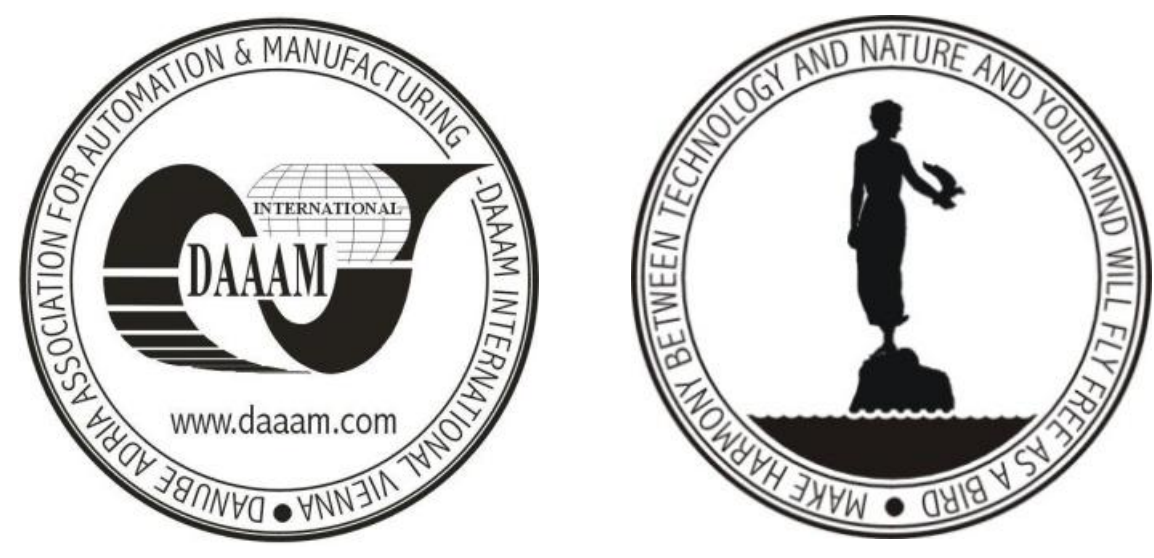

Authors' data: Univ.Prof. Comanescu, D[inu]; Assoc. Prof. Comanescu A[driana]; Assoc. Prof. Filipoiu I[oan] D[an]; Alionte C[ristian] G[abriel], University Politehnica of Bucharest, Splaiul Independentei 313, 060042, Bucharest, Romania, dinucomanescu@yahoo.com, adrianacomanescu@yahoo.com, ioan.filipoiu@upb.ro, a_cgabriel@yahoo.com

This Publication has to be referred as: Comanescu, D[inu]; Comanescu A[driana]; Assoc. Prof. Filipoiu I[oan] D[an] \& Alionte C[ristian] G[abriel] (2010). A New Heat Pipe Cooling Device, Chapter 52 in DAAAM International Scientific Book 2010, pp. 593-606, B. Katalinic (Ed.), Published by DAAAM International, ISBN 978-3901509-74-2, ISSN 1726-9687, Vienna, Austria

DOI: $10.2507 /$ daaam.scibook.2010.52 


\section{Introduction}

The fractals are well studied from mathematical point of view. Their simulation and their assimilation with various forms existing in the nature are also presented in the literature. By using proper design software the Peano, Hilbert and Koch profile parameters are used to obtain optimal constructions (Barnsley \& Demko, 1986).

The paper presents a specific application of fractals, which are used in a heat pipe cooling device. This new device type was developed for some years in Politehnica University of Bucharest by a group of multi-disciplinary group researchers lead by this paper authors. The research found some original aspects unfound in the technical literature. Firstly mentioned on this occasion there are also specified new development research directions, which may be achieved on adequate projects. The paper presents only the geometrical and mathematical aspects of the fractals applications in the cooling of IT devices parts, with focusing on the heat pipe parts geometrical design. It is also presented some basic calculus regarding cooling design the optimization of this cooling devices will be subject of future work.

\section{Heat pipes}

In this chapter will be presented some basics aspects of heat pipes. The heat pipe is composed of three basic components (Zaghdoudi et al., 2004):

- the container;

- the working fluid;

- the wick or capillary structure which has a fractal form (two plates: superior and inferior) which can be placed in mobile computer structures. (Fig. $1)$.

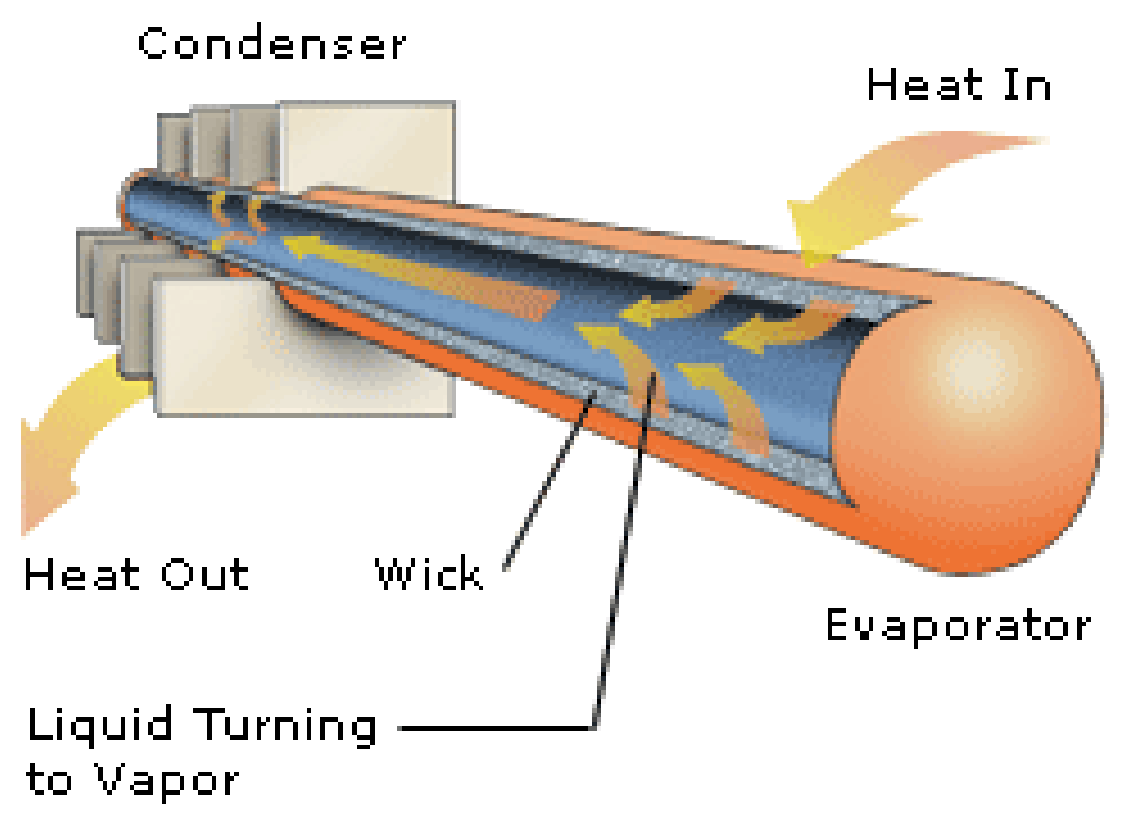

Fig. 1. Heat pipe $(* * *, 2006)$ 
Working fluid under its own pressure is vaporized in the evaporator and flows toward the condenser, wetting all internal surfaces, where it deposits its heat by condensation, because the liquid will be transformed in vapor state by boiling. In the porous wick, the capillary forces return the condensed working fluid to the evaporator. Operation takes place at virtually the same temperature and does not depend on where the heat enters or leaves the heat pipe. The function of the container is to isolate the working fluid from the outside environment. It has to therefore be leak-proof, maintain the pressure differential across its walls, and enable transfer of heat to take place from and into the working fluid (Sobhan, 2005).

A heat pipe by itself does not remove or dissipate heat. It is only a conduit through which heat can be moved from one point to another with a low thermal resistance. To make it operational, a heat pipe must have as much cooling surface area in form of fins as the equivalent-size air-cooled heat sink without a heat pipe.

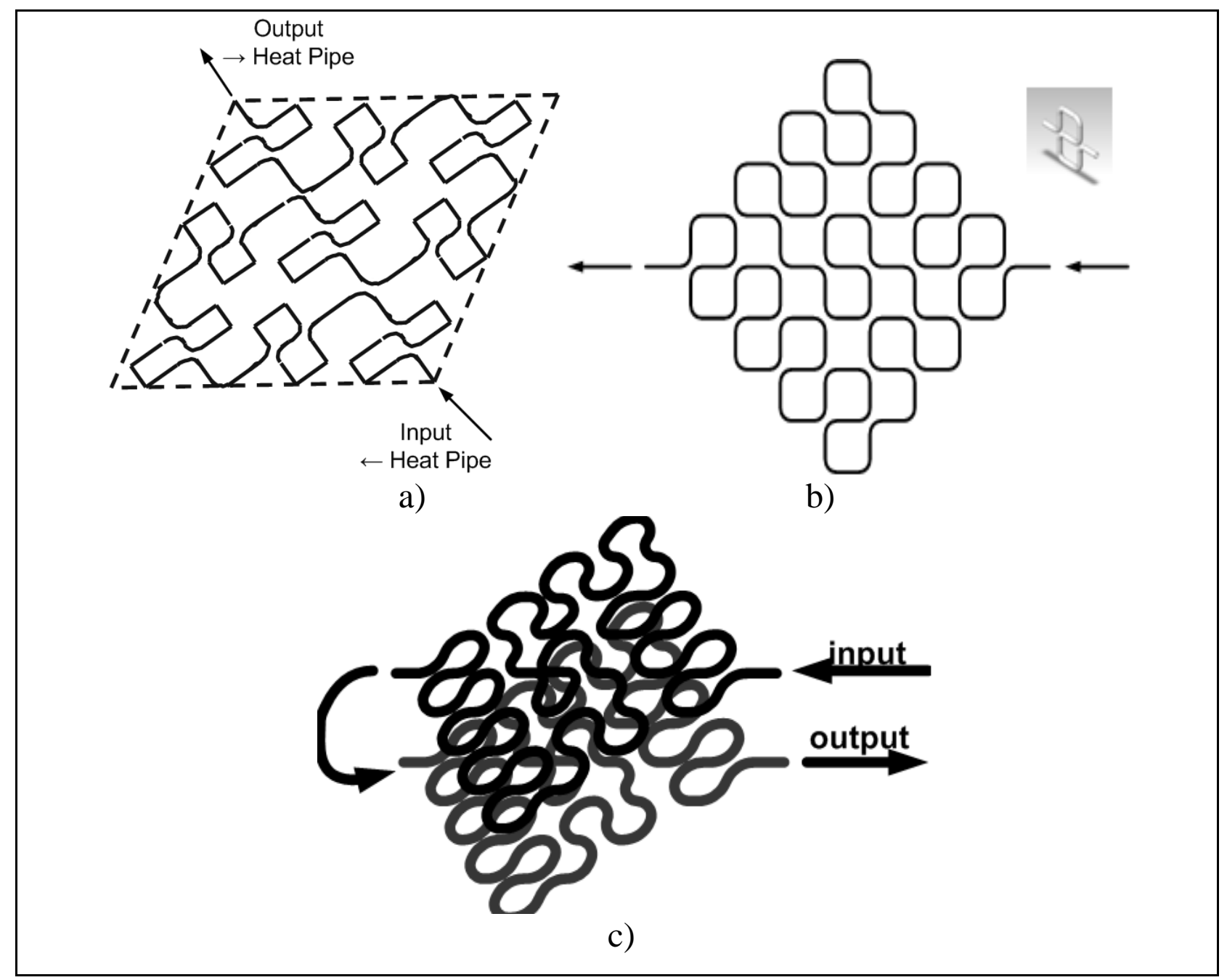

Fig. 2. The fractal capillary structure

As can be seen in Fig. 2 the heat pipes based on the fractal networks can have different input/output configurations. In Fig. 2a is presented a heat pipe with an input and an output in different planes, in Fig. $2 b$ is presented a heat pipe with the input and the output in the same plane and in Fig. $2 \mathrm{c}$ is presented a two layers heat pipe. 
Selection of the container material depends on many factors (Shankara Narayanan 2006). these are as follows:

- Compatibility (both with working fluid and external environment);

- Strength to weight ratio;

- Thermal conductivity;

- Ease of fabrication, including welding, machine ability and ductility;

- Porosity;

- Wet ability.

A high thermal conductivity ensures a minimum temperature drop between the heat source and the wick.

\section{Fractals used in a heat pipe cooling device}

In this chapter are presented some mathematical aspects which define the form, the construction and constrain the design of the fractal networks used in heat pipe cooling devices. Having in view the geometrical characteristics, the Peano curve fractal may be used for heat pipe device. In this situation the section of such a system are chosen in function of other requirements (heat transfer, flow, technological manufacturing, etc).

The main property of this curve, which its fractal dimension is two (Voinea \& Stroe, 2000), is that a square may be filled with it (Fig. 3d). For example a Peano curve is built by Hilbert (Fig. 3a). By using the property of its auto-similarity one may determine its fractal dimension, which it is also two as in the previous case (Voinea \& Stroe, 2000).

The auto-similarity is a characteristic property of the mathematical fractals. This is the main difference between a mathematical fractal and a natural one, which it is governed by the dynamic phenomena, as such of growing.

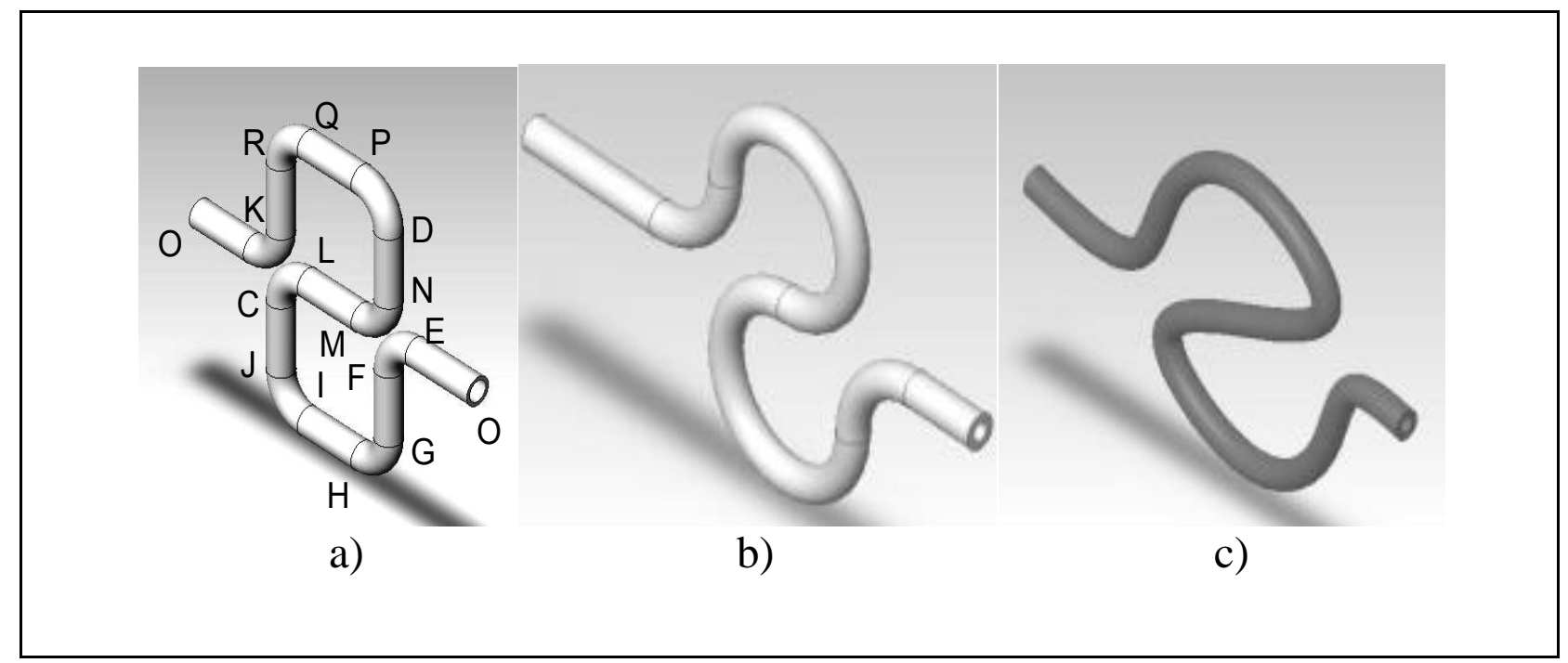

Fig. 3. Peano units with various forms: a) Hilbert curve; b) Hutchinson curve;

c) Koch curve 
By assumption the Hutchinson operator (Fig. 3b) as a succession of affine transformation operators (translation, rotation, reducing by similitude, affine reducing, mirror, cutting) a fractal appears as a fixed point of this operator.

In the case of the Koch curve (Fig. 3c) the Hutchinson operator (W) is composed successively by a $1 / 3$ contraction for the OB segment (W1), followed by a 600 rotation and a $1 / 3$ translation for the BC segment (W2), a similar transformation for the CD segment (W3) and a 1/3 contraction with a translation for the DK segment (W4), so that

$$
W=W_{1} \cup W_{2} \cup W_{3} \cup W_{4}
$$

The final curve may be obtained as follows:

$$
\begin{array}{cc}
O E=W_{1}\left(W_{1} A_{0}\right) & E F=W_{1}\left(W_{2} A_{0}\right) \\
F G=W_{1}\left(W_{3} A_{0}\right) & G B=W_{1}\left(W_{4} A_{0}\right) \\
B H=W_{2}\left(W_{1} A_{0}\right) & H I=W_{2}\left(W_{2} A_{0}\right) \\
I J=W_{2}\left(W_{3} A_{0}\right) & J C=W_{2}\left(W_{4} A_{0}\right) \\
C L=W_{3}\left(W_{1} A_{0}\right) & L M=W_{3}\left(W_{2} A_{0}\right) \\
M N=W_{3}\left(W_{3} A_{0}\right) & N D=W_{3}\left(W_{4} A_{0}\right) \\
D P=W_{4}\left(W_{1} A_{0}\right) & P Q=W_{4}\left(W_{2} A_{0}\right) \\
Q R=W_{4}\left(W_{3} A_{0}\right) & R K=W_{4}\left(W_{4} A_{0}\right)
\end{array}
$$

the $\mathrm{W}$ operator previously defined generating by successive iterations the Koch curve.

The previous units are inserted in Peano type networks, Fig. 4. The structures based on the Hilbert (Fig. 4a) and Hutchinson (Fig. 4b) curve and with different sections are possible to be used for units or heat transfer pipes and networks.

The last constructions (Fig. 4c) are based on the Koch curve. Even if they have rather strange image these are the first steps to attempt new field of applications for other fractals as Barnsley fern.

Similarly, the structures based on the Hilbert curve and with different sections (Fig. 5) are possible to be used for units or heat transfer pipes and networks.

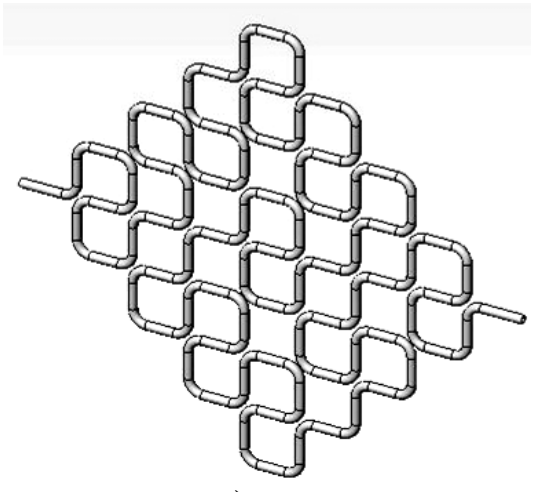

a)

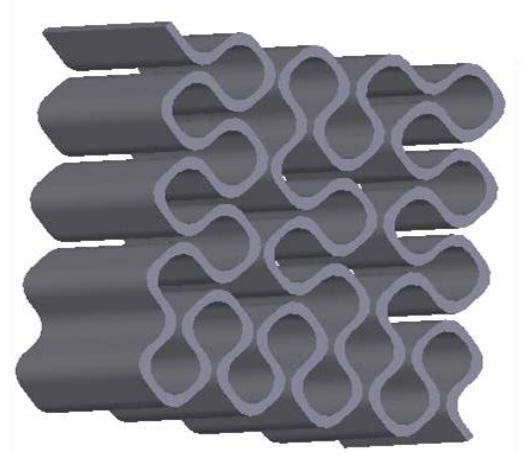

b)

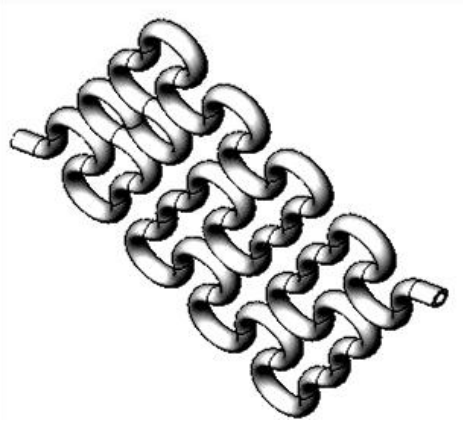

c)

Fig. 4. Hilbert networks 
The previously mentioned structures are suitable for many technical applications even in the computer and other mechatronics equipments. It is also important to underline the possible connections to the human body and these will be the next coordinates of research.
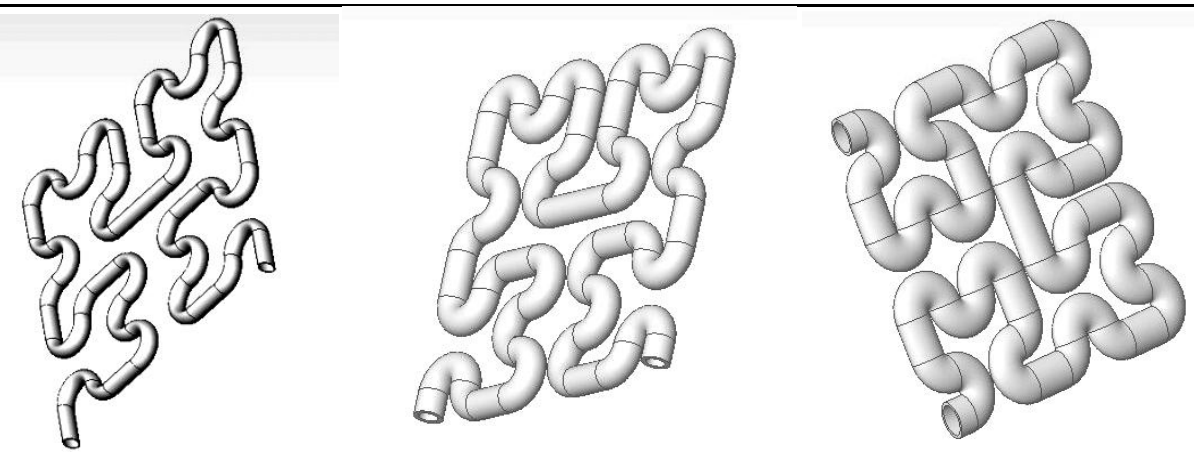

Fig. 5. Hutchinson networks

All these constructions have been partially analyzed from the previously mentioned points of view.

The last constructions (Fig. 6) are based on the Koch curve. Even if they have rather strange image these are the first steps to attempt new field of applications for other fractals as Barnsley fern.
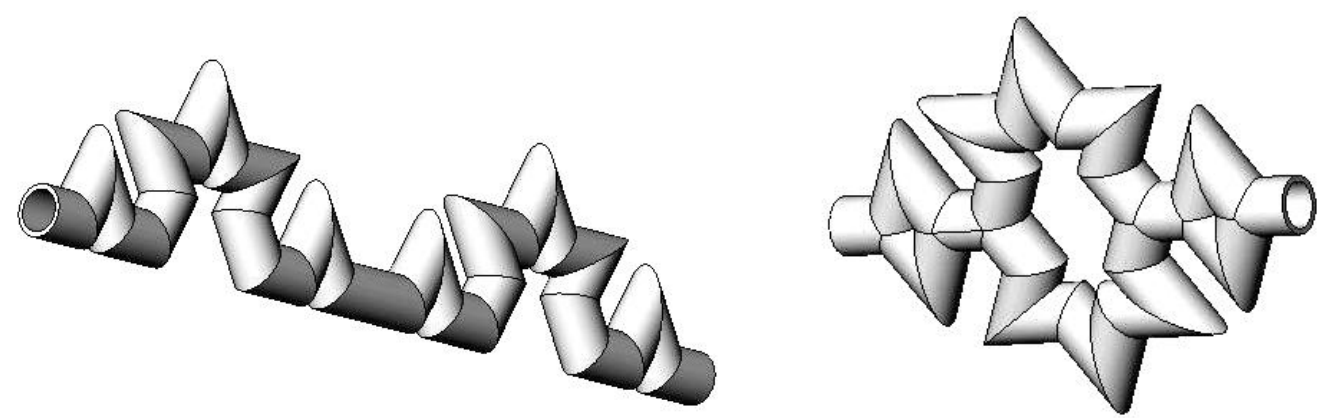

Fig. 6. Koch networks

The research may be developed as in its fundamental bases as in various directions including the fractal generation for new technical applications, their connection with the human body and the human body systems prosthetics based on fractal theory.

But one of the principal applications can be the using of the fractals networks in the cooling devices. An example of using the fractals in the cooling devices using also a heat pipe is presented in the Fig.7. This device has a classical design with condenser and vaporizer, the heat pipe make only a link between the two parts. Also, the devices can have one layer or two layers; can be in the same plane or on perpendicular plane. 


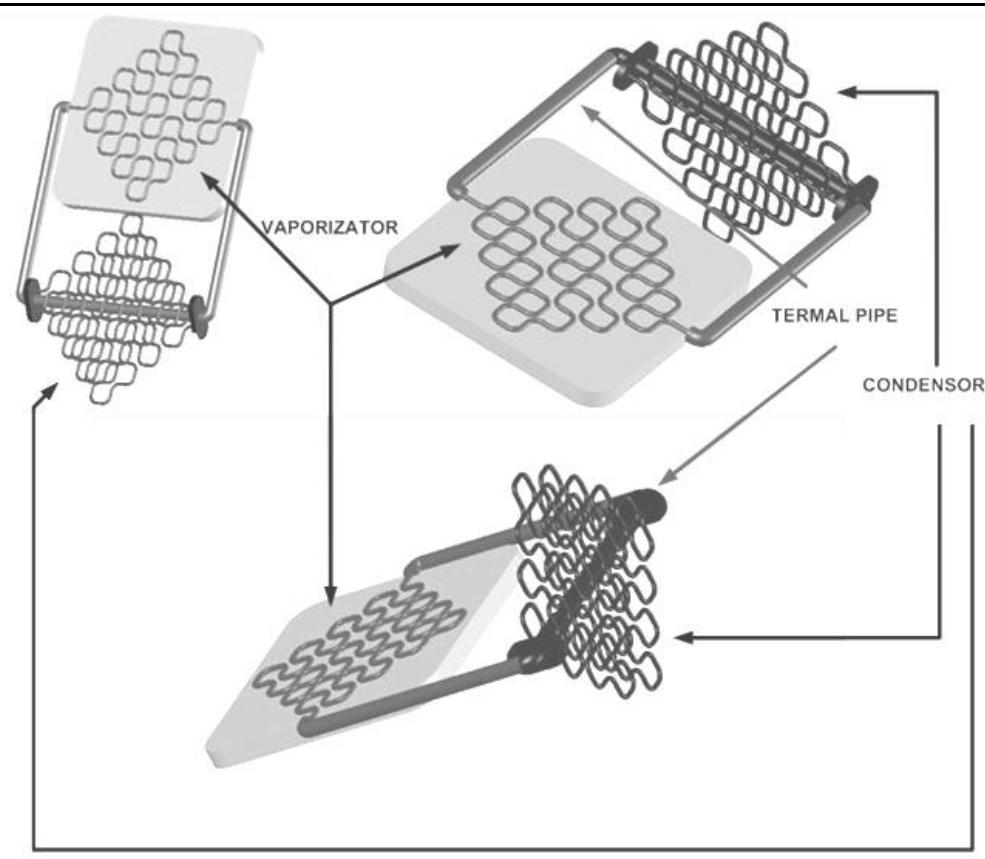

Fig. 7. Fractal cooling device

The condenser and the vaporizer can be designed as fractal networks with one layer, two layers or more. In the Fig. 8a and Fig. $8 \mathrm{~b}$ can be seen a heat pipe with two layers with one input and one output.
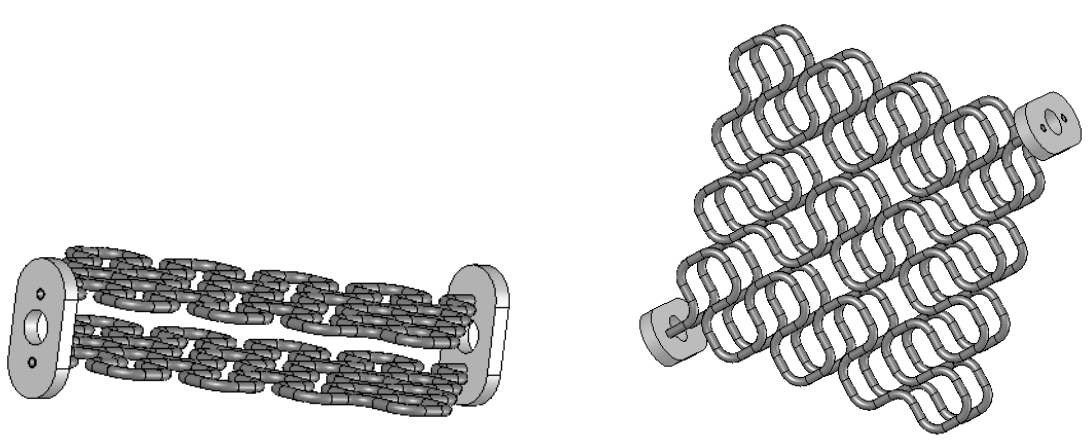

Fig. 8. Fractal networks with two layers

Based on the construction mentioned above, we built several cooling designs, which are presented in the Fig. 9. In the Fig. 9a is presented a basic cooling device mounted on a processor. In Fig. 9b, Fig. 9c and Fig. 9d are presented some Hilbert networks and in Fig. 9e, Fig. 9f and Fig. 9g are presented Hutchinson networks with one layer and different constant thicknesses. We mentioned here that the form of the condenser and vaporizer had two variation parameters: the number of the fractals and the thickness. The link between the two parts depends as form and length because the variation parameters of the condenser and vaporizer, because the only design constraint for the heat pipe was minimum length. 
Comanescu, A.; Comanescu, D.; Filipoiu, I.D. \& Alionte, C.G.: A new Heat ...

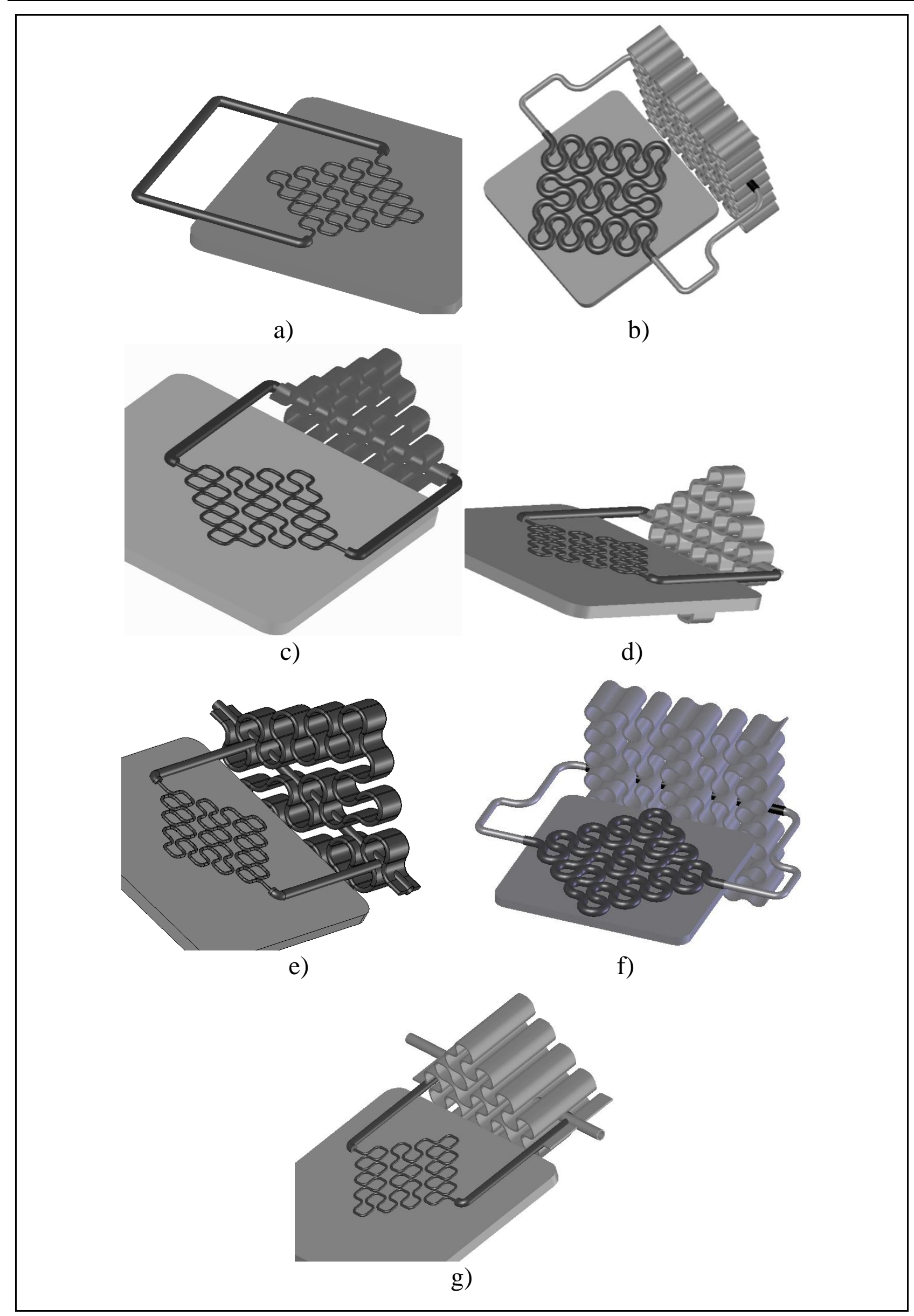

Fig. 9. Fractal networks with constant thicknesses 
Also, the fractals design depends on the fractal type. In Fig. 10a and Fig. 10b are presented Hilbert networks and in Fig. 10e, Fig. 10f and Fig. 10g are presented Hutchinson with one layer and different thicknesses which is variable.

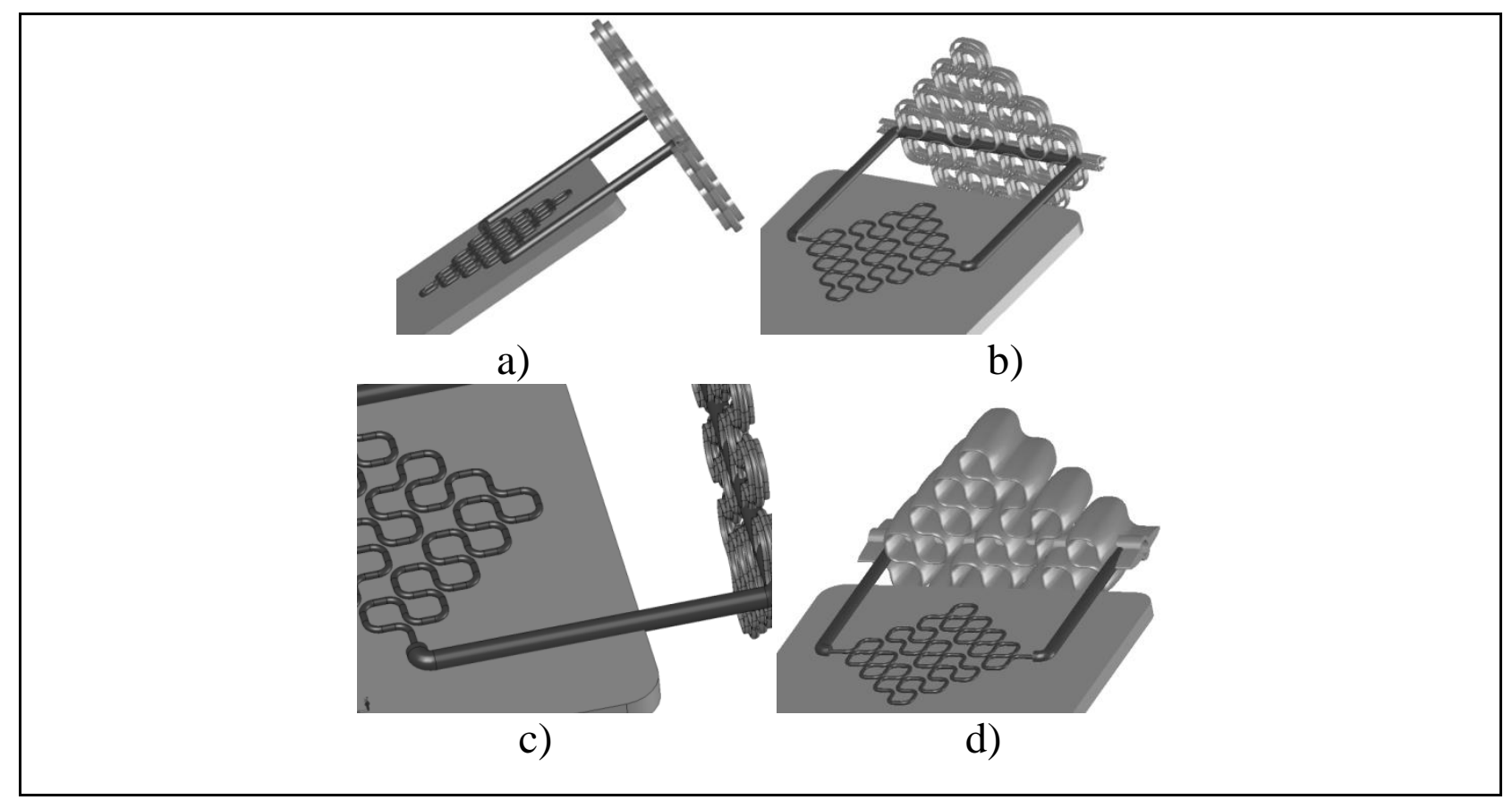

Fig. 10. Fractal networks with constant thicknesses

And finally, in Fig. 11a and Fig. 11b are presented Hilbert networks and in Fig. 11c and Fig. 11d are presented Hutchinson layers with two layers and constant thicknesses.

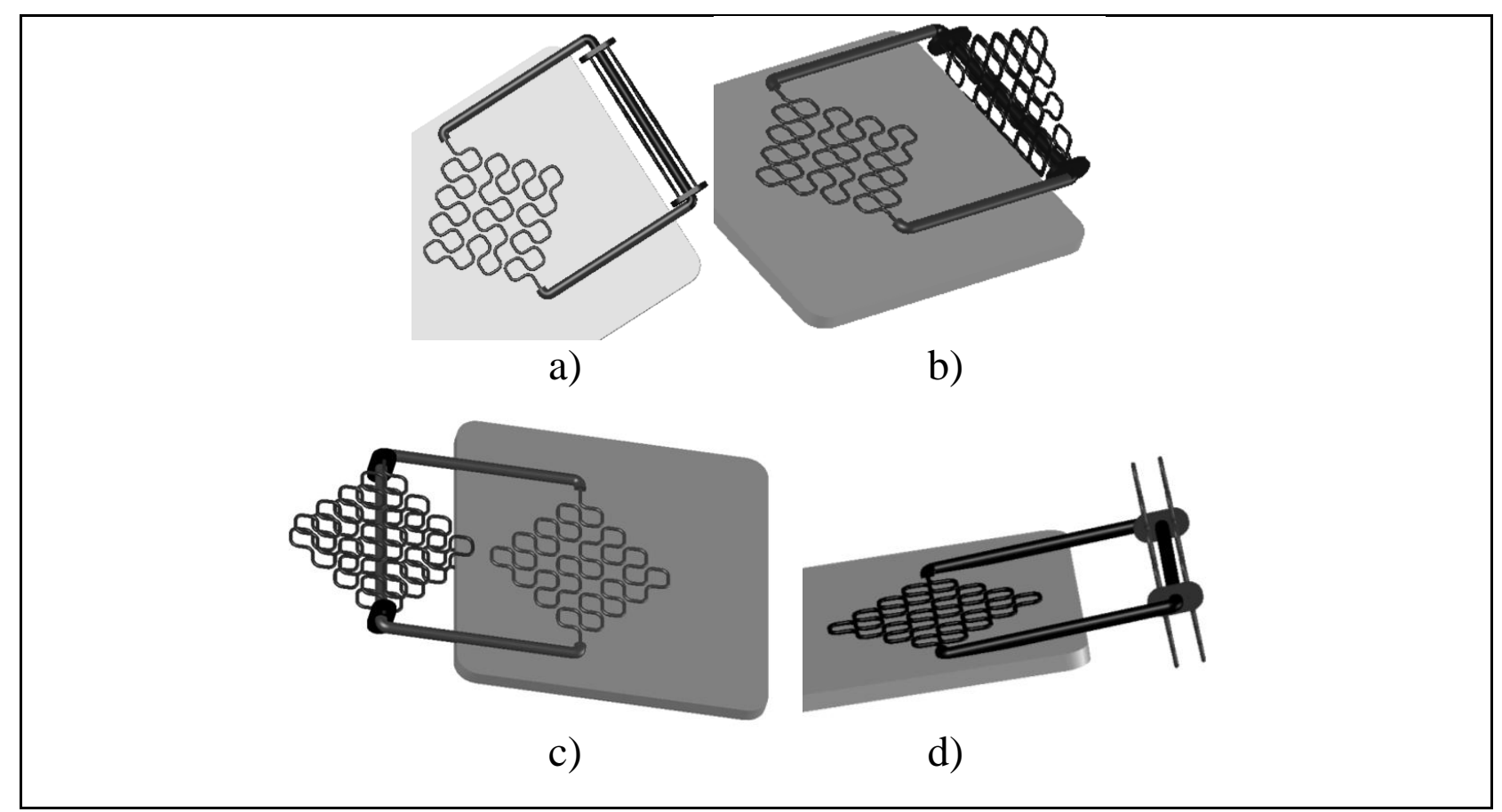

Fig. 11. Fractal networks with two layers 


\section{Testing data results}

In this chapter is presented a basic test used to validate the fractal application as cooling devices. For validation, basic tests have been conducted. In Fig. 15 is presented the experimental test equipment. Inside the container, placed on the heating system, is a liquid. Under its own pressure the liquid enters in the pores of the capillary material and is wetting all internal surfaces. Applying heat at any point along the surface of the heat pipe causes the liquid at that point to boil and enter in a vapor state. When that happens, the liquid picks up the latent heat of vaporization. The gas has a higher pressure, moves inside the sealed container to a colder location where it condenses.

Thus, the gas gives up the latent heat of vaporization and moves heat from the input to the output end of the heat pipe. This entire cycle usually happens with less than a $5^{\circ} \mathrm{C}$ differential from one end of the pipe to another. We used in the experiments the simplest type of wick structure, double-layer fractal mesh screen wick. The geometric and thermo physical properties of the wick have been selected are presented in the Table 1. Based on hereinbefore fractal capillary structure we obtained the following heat pipe specifications:

- Horizontal orientation;

- Maximum heat transfer: $30 \mathrm{~W}$;

- Nominal operating temperature: $40^{\circ} \mathrm{C}$;

- Pipe diameter: $0.08 \mathrm{~m}$;

- Heat Pipe length: Evaporator: 0.04 m; Adiabatic: 0.05 m; Condenser: 0.07 m.

\section{Examples of using fractals in heat pipe devices}

In this chapter we are presenting some examples of using fractals in heat pipes design.

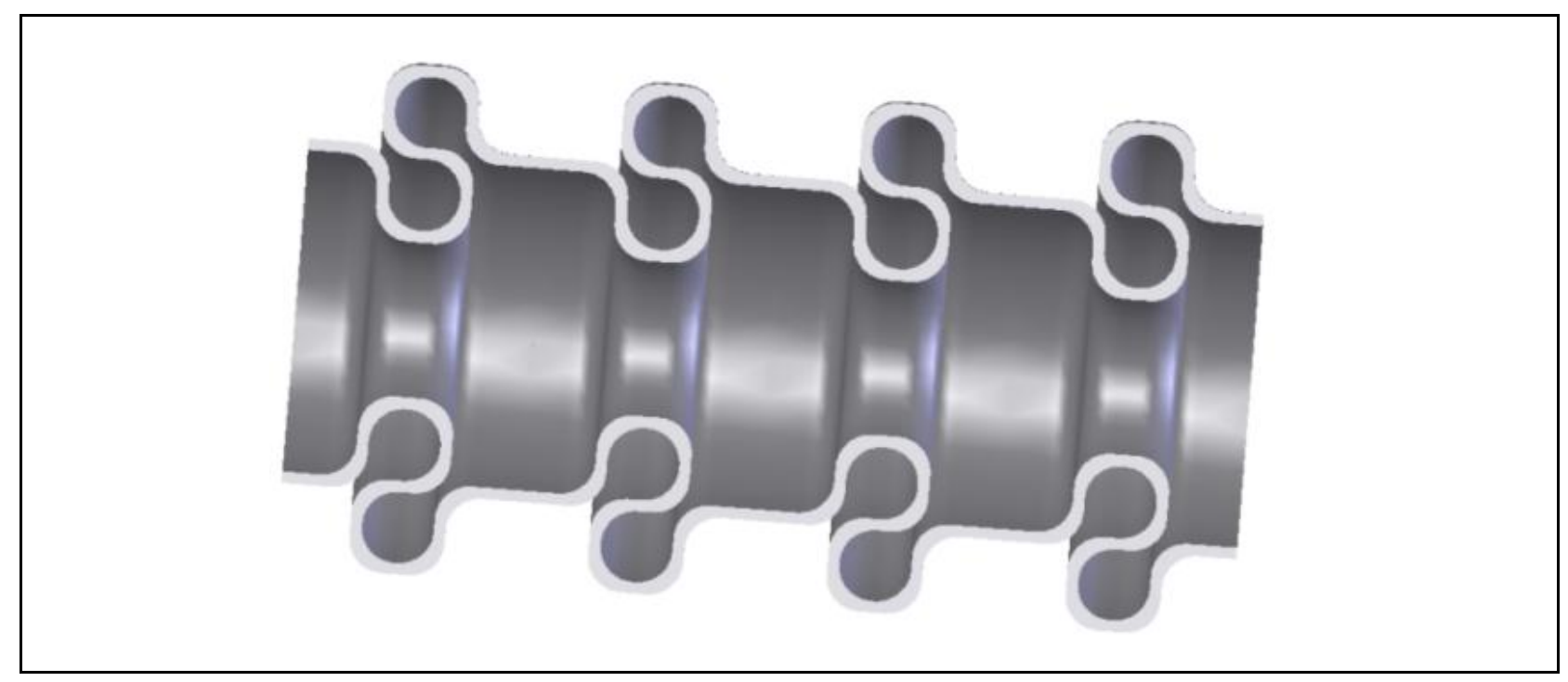

Fig. 12. Fractal networks used as heat pipe 
One possibility to design is to have a different form in the condenser area of the heat tube, Fig. 12. This is not a good solution because the fluid has a slow displacement caused by the modification of the tube wall form and dimension. It is well known that the speed of the displacement of the fluid influence directly the number of the faze shifts, and influence directly the efficiency of the heat pipe.

By using thermal pipes the fractal using is focused on the condenser part. These are shown in the Fig.13. In the Fig. 13a is presented a condenser which consists of one ring fastened on the thermal pipe and an annular fractal Koch network. In the Fig. $13 \mathrm{~b}$ is presented a condenser which consists of umbrella type fractal Koch network. In the Fig. 13c, Fig. 13d and Fig. 13e are presented some condenser forms which consist of several Hilbert network rings fastened on the thermal pipe. As is known, the bigger are the cooling surfaces the performance is increased. In the future research we will study which is the influence of the form and the dimension of the surface. Also, we will study the influence of the distance between surfaces, the gaps dimension, which are depending only because of the type of fractal.

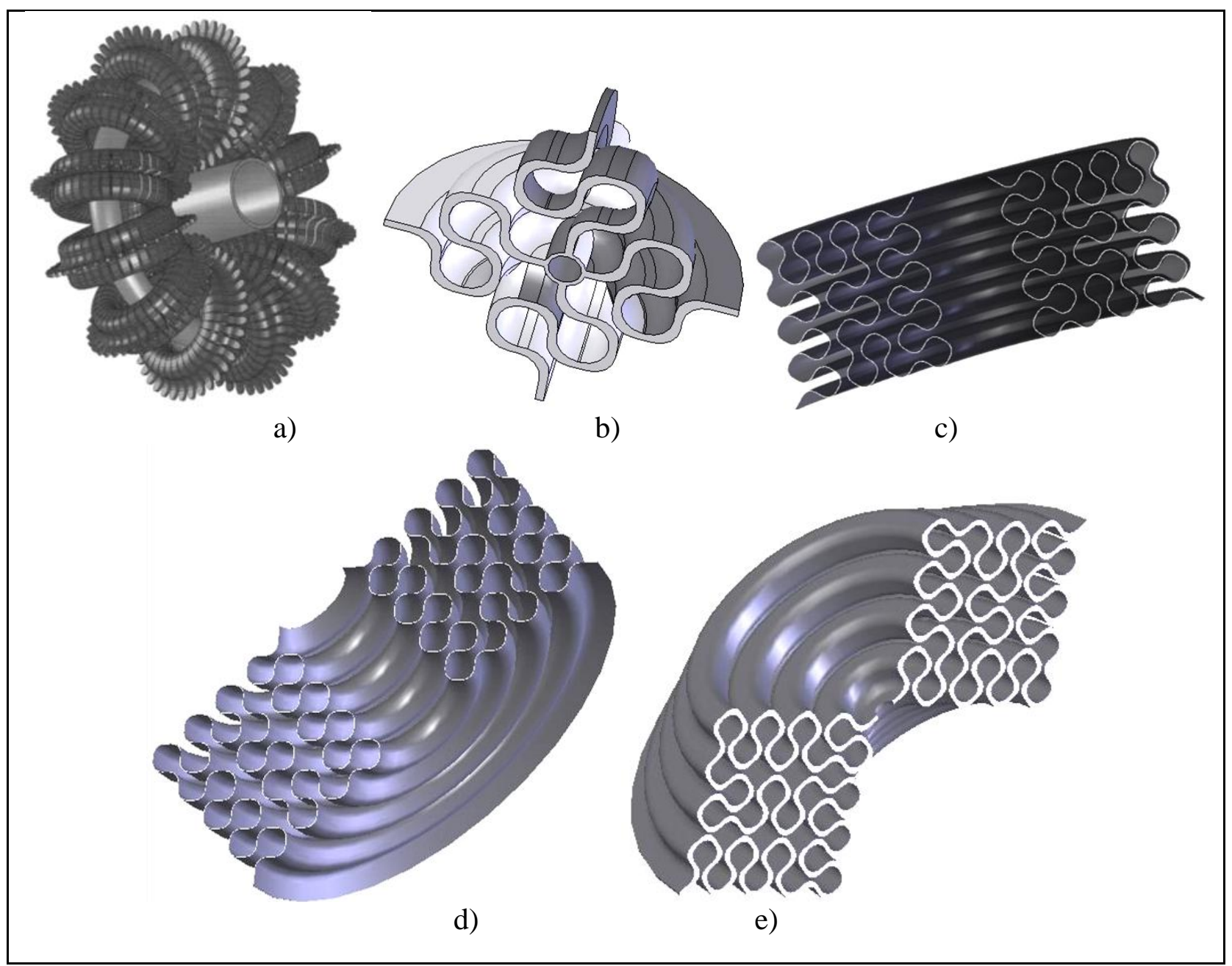

Fig. 13. Fractal networks used as condenser level

Another possibility to design and the simplest one is to put standard fractal networks in the condenser area of the heat tube. In the Fig. 14a, Fig. 14b and Fig. 
Comanescu, A.; Comanescu, D.; Filipoiu, I.D. \& Alionte, C.G.: A new Heat ...

$14 \mathrm{c}$ different types of condensers are presented. The solutions presented in Fig. 14b and Fig. 14C has the advantage of the small occupied volume.

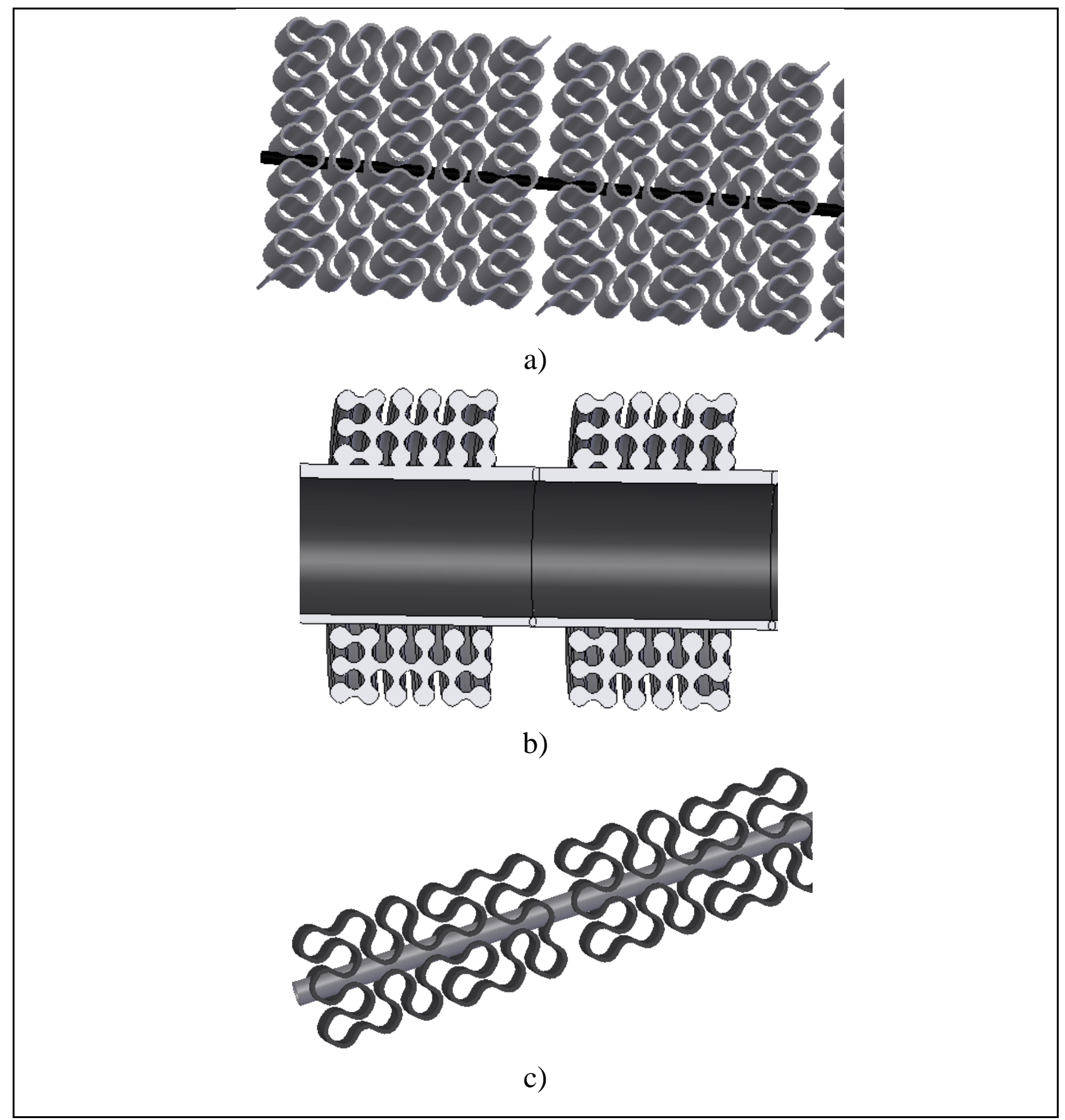

Fig. 14. Fractal networks used as condenser level

\section{Conclusions}

The main purpose of this paper is that to find some new structures for the laptops and notebooks cooling systems. In order to increase its transfer efficiency and shape minimization the authors firstly use various fractals configuration as thin plates with large cooling surfaces. Because they are thin, the plates can be used in cooling device where the dimensions are critical. 
We designed a water heat pipe able to transport $30 \mathrm{~W}$ of waste heat from a mobile computer CPU.

Based on the space available inside the mobile computer case, the location of the CPU and the exhausts vents, we will choose the following heat pipe specifications:

1. Horizontal orientation

2. Maximum heat transfer: $30 \mathrm{~W}$

3 Nominal operating temperature $-40^{\circ} \mathrm{C}$

4. Pipe diameter $-0.08 \mathrm{~m}$

5. Heat Pipe length:

- Evaporator: $0.04 \mathrm{~m}$

- Adiabatic: $0.05 \mathrm{~m}$

- Condenser: $0.07 \mathrm{~m}$

The simplest type of wick structure to use is a single-layer wire mesh screen wick shown in Table 1.

\begin{tabular}{|l|c|}
\hline \multicolumn{1}{|c|}{ Geometric properties } & Value \\
\hline wick diameter & $2 \times 10^{-5} \mathrm{~m}$ \\
\hline wick width & $1.2 \times 10^{-4} \mathrm{~m}$ \\
\hline working temperature & $313.15 \mathrm{~K}$ \\
\hline $\begin{array}{l}\text { heat pipe radius of the } \\
\text { cylinder }\end{array}$ & $3.5 \times 10^{-3} \mathrm{~m}$ \\
\hline $\begin{array}{l}\text { heat pipe inner radius of } \\
\text { the cylinder }\end{array}$ & $3.38 \times 10^{-3} \mathrm{~m}$ \\
\hline $\begin{array}{l}\text { effective length of the } \\
\text { heat pipe }\end{array}$ & $0.115 \mathrm{~m}$ \\
\hline $\begin{array}{l}\text { total length of the heat } \\
\text { pipe }\end{array}$ & $0.16 \mathrm{~m}$ \\
\hline $\begin{array}{l}\text { cross-sectional area of } \\
\text { the wick structure }\end{array}$ & $2.971 \times 10^{-6} \mathrm{~m}$ \\
\hline
\end{tabular}

Tab. 1. Geometric properties of the heat pipe device

The design was validated through basic experimental tests which demonstrate the cooling capability of this structure (maximum heat transfer is $30 \mathrm{~W}$ ). All of the heat transfer limitations, with the exception of the boiling limitation, exceed the specified heat transfer rate of $30 \mathrm{~W}$. The low value of $0.131 \mathrm{~W}$ for the boiling limitation strongly suggests that the liquid will boil in the evaporator and possibly cause local dry spots to develop. The reason the liquid boils is because the effective thermal conductivity of the wick is equal to the conductivity of the liquid, which is very low in this case. Because the liquid is saturated at the vapor-liquid interface, a low effective thermal conductivity requires a large amount of wall superheat which, in turn, causes the liquid to boil. This problem can be circumvented by using a high conductivity wire mesh or sintered metal wick, which greatly increases the effective conductivity. It should be noted, however, that because porous wicks have lower permeabilities, the capillary limitation should be lower as well. 
The future researches include: optimizing the structures, researches regarding different cooling fluid using an investigation of full cooling characteristics of this device.

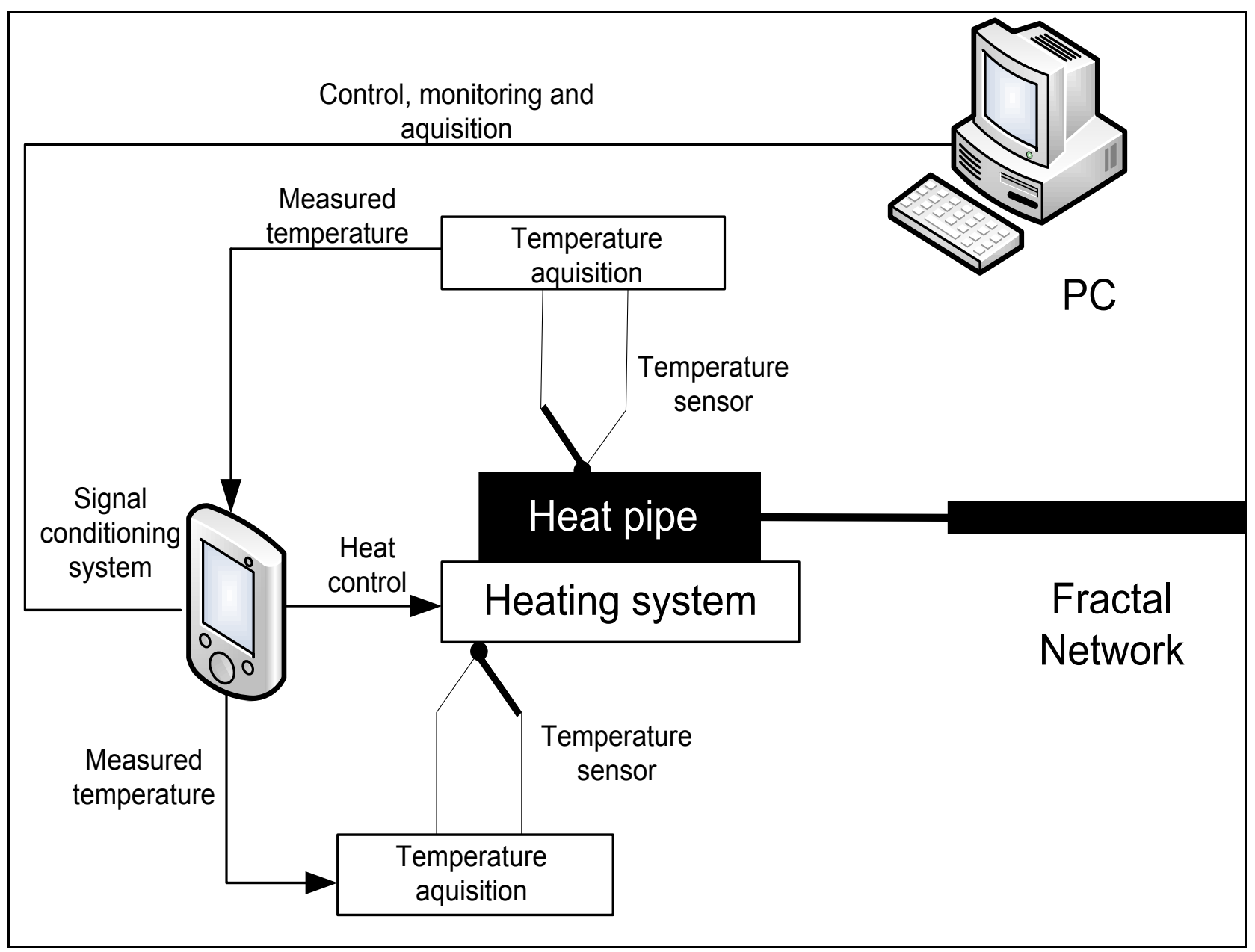

Fig. 15. Experimental test equipment

\section{References}

Voinea, R. \& Stroe, I. (2000). Introduction in theory of dynamical systems, Ed. Academiei Romane, ISBN 973-27-0739 - 9, Bucharest

Barnsley, M. F. \& Demko, S. (1986). Chaotic Dynamics and Fractals, Academic Press ISBN 0120790602

Zaghdoudi M. C.; Tantolin C. \& Godet C. (2004). Use Of Heat Pipe Cooling Systems In The Electronics Industry. Available from: http://www.electronicscooling.com/html/2004_nov_al.html Accessed: 2005-06-20

Sobhan B. C. (2005). Modeling of the Flow and Heat Transfer in Micro Heat Pipes. Available from: http://www.rpi.edu/tphtl/research/mfht/mfht.html Accessed: 2006-07-20

Shankara Narayanan K.R. (2006). What's A Heat Pipe? Available from: http://www.cheresources.com/htpipes.shtml Accessed: 2006-06-16 *** (2006). Heat Pipe Technology, Available from: http://www.thermacore.com/Technologies/heat-pipe-technologies.aspx Accessed: 2006-07-16 